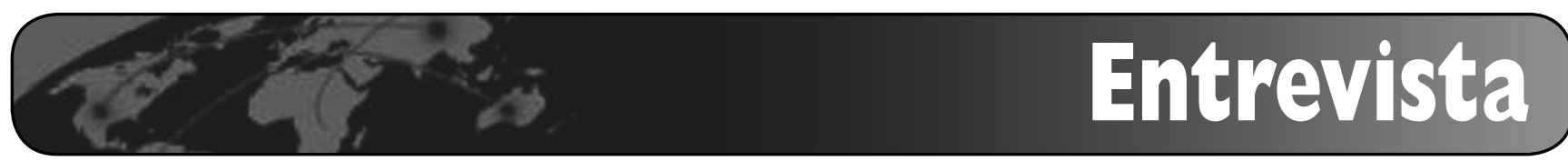

\title{
Information architecture \& findability: Peter Morville interview
}

\author{
Por Mari-Carmen Marcos
}

\begin{abstract}
Marcos, Mari-Carmen. "Information architecture \& findability: Peter Morville interview". En: El profesional de la información, 2007, mayo-junio, v. 16, n. 3, pp. 268-269.
\end{abstract}

DOI: 10.3145/epi.2007.may.12

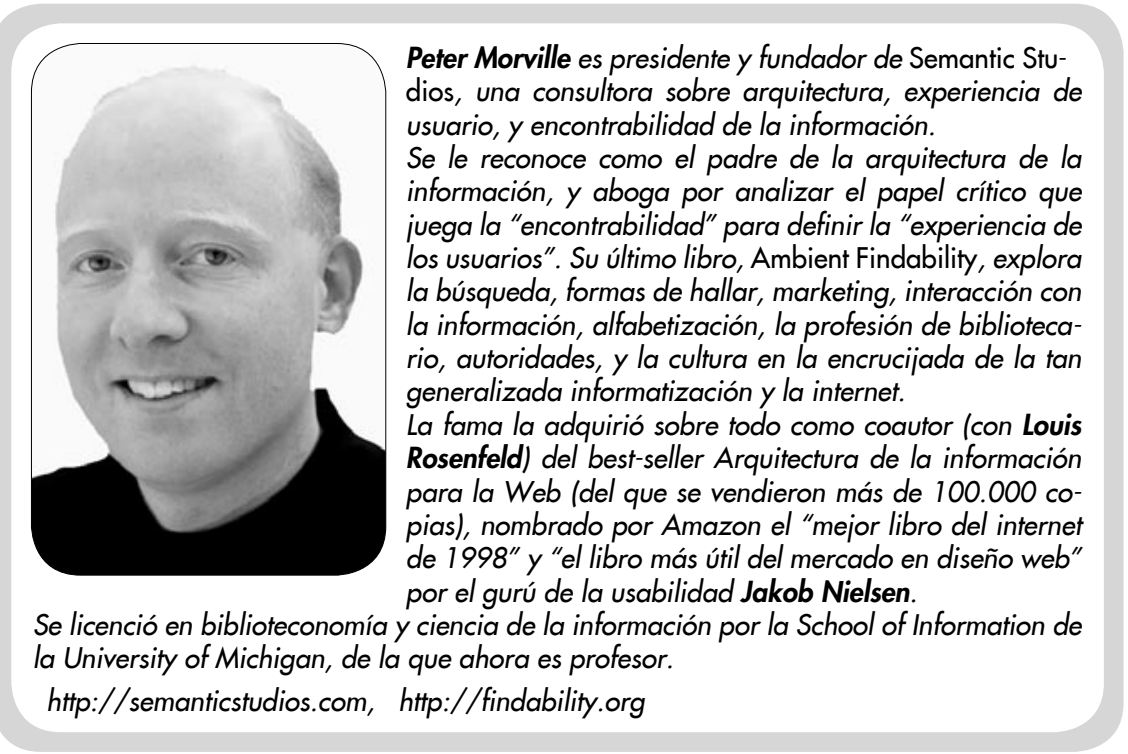

Nowadays information architecture (IA) is not a new area. In fact, it is a necessity for successful websites. But what is IA and what is not?

-At its core, information architecture involves the design of organization, search, and navigation systems that shape the user experience. The Web gave birth to the profession and community of practice, but IA principles can be applied to all types of media, channels, environments, and products. The soft edges that connect IA to other disciplines present tremendous opportunity for innovation, so I prefer to embrace fuzziness rather than draw lines and define boundaries.

IA and interaction design: will they be friends forever?

-IA and interaction design are sister disciplines. As such, they are best friends and worst enemies. As our interfaces become richer, the lines between finding and interacting will fade, so it's in our best interests to learn from one another. I expect that collaboration and rivalry between the two communities will endure.

One key post in website design is the information architect. But what kind of people should be part of an IA team? What should their training be? What professions should form the IA community?

-Most web teams don't need a full-time information architect, but they do need someone - perhaps a producer or visual designer - with solid IA skills. For teams that require and can afford a specialist, graduates of programs that combine library and information sci- ence with human-computer interaction often have the best educational credentials. But, there's no substitute for experience. Look for candidates who have worked in multidisciplinary teams to create successful information architecture solutions.

Many people find it difficult to explain to clients how IA contributes to the success of websites. What arguments can we provide?

-The simplest case builds on three findability questions:

1. Can your users find your web site?

2. Can your users find their way around your web site?

3. Can your users find your products and content despite your web site?

Findability is the major problem with most large web sites today, and information architecture is a big part of the solution. Of course, as I've shown with my user experi-

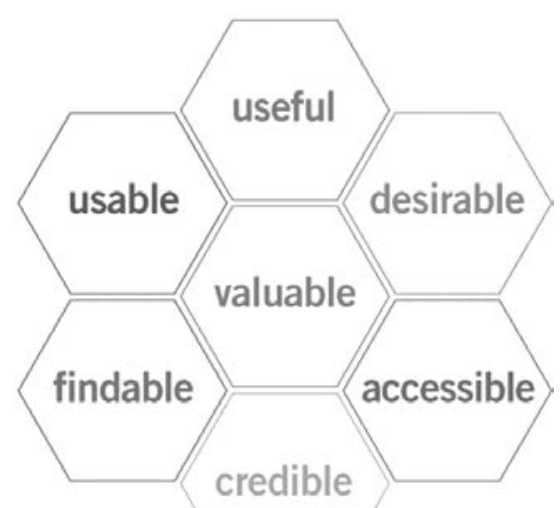


ence honeycomb [figure 1], IA isn't just about findability, but is also essential to designing products that are useful, usable, desirable, accessible, and credible. I can't overstate the role that information architecture plays in shaping a company's brand.

Tags are a new way to describe information in Web 2.0 applications. How does free tagging affect navigation and IA?

-For a few sites such as Flickr, user-contributed tags (along with popularity metrics such as "interestingness") are central to navigation, although even Flickr relies on a global navigation bar with traditional categories and subcategories. For most sites, tags and folksonomies play no role. In other words, there's a lot of IA in Web 2.0, but there's even more IA outside Web 2.0 .

That said, I'm very interested in exploring the simultaneous use of both tags and taxonomies to enable user participation, collective intelligence, and semantic agility while maintaining structure, stability, and semantic precision. As we've learned again and again, the old needn't make way for the new. Instead, the innovative combination of old and new is better than either solution alone.

Log analyses, especially navigation and query tracking, are great ways to get to know user behavior. What should we take into account to make the most of data mining?

-In my consulting projects, I study the query logs to better understand what users are searching for and what words they use. But my analyses are quite basic compared to what's possible given the necessary time and tools. For instance, at last year's IA Retreat in Chile, Ricardo Baeza-Yates gave a fascinating lecture about mining search query data at Yahoo! that included some very sophisticated analysis of user behavior. And my colleague, Louis Rosenfeld, will soon publish a new book about Search Analytics. So, this is clearly an area of great interest from the perspectives of both research and practice.

When should we conduct user observation tests? Should they be done in a real context or in a lab? Are interviews and surveys really useful?

-User testing should be an element of almost every project. I generally spend a day on six to eight one-hour user research sessions that combine interviews with testing, but even a single session can provide both insight and motivation (empathy for the user). Surveys are useful for learning about user priorities (e.g., which features are most important) but when it comes to IA, there's often a gap between what users say and what users do. Proceed with caution!

You wrote an article called "Information Architecture 3.0." What is the difference between IA 1.0, 2.0, and 3.0?

-When I named and wrote that article, I intended to be both funny and serious. On one hand, I was making fun of the hyperbole that surrounds Web 2.0. The Web grows and changes every day. There is no step change. There are no versions. On the other hand, Web 2.0 celebrates the distance we've traveled since the early 1990s. User participation, co-creation, tagging, syndication, mashups, and rich interfaces enable us to venture beyond html and beyond the page. We might think of IA 2.0 as IA for Web 2.0. This is an exciting, entrepreneurial space with lots of IA challenges, but again, most IA happens outside Web 2.0.

So, IA 3.0 points to a fast-emerging future in which we've begun to successfully integrate classic and post-modern IA into mainstream applications, and in which we've begun to stretch IA beyond the Web into cross-channel and transmedia solutions that intertwingle physical and digital experiences.

What is the impact do you think Web mobile devices will have on IA work?

-My latest book, Ambient Findability, describes a world in which we can find anyone or anything from anywhere at anytime. Thanks to GPS, rfid, cellular triangulation, and many other locating-sensing technologies, we will soon be able to tag and track products, pets, possessions, places, and each other. In this geospatial web, where walking is a form of querying, the IA challenges are huge. We'll need twice as many IAs, and they'll all need to be twice as smart.

How would you encourage readers of the first and second edition to read the third?

-If you've read the first and second editions, then buy the third and give it to a friend. They need it more than you do.

We know that you will be at USID this year. What will your session and your seminar be about and why should people be encouraged to go?

-It's hard to precisely describe the aboutness of my sessions. If subjected to textual analysis, statistically improbable phrases might include information architecture, ambient findability, sociosemantic web, ubiquitous findable object, polar bear, and lemur. So, why should you come? Because I'm much funnier in person.

Mari-Carmen Marcos, mcarmen.marcos@upf.edu http://www.mcmarcos.com/ 